\title{
How Prepared are Malaysian Nurses for Online Distance Learning?
}

\author{
Zoraini Wati Abas \\ International Medical \\ University, \\ Kuala Lumpur, Malaysia \\ zwabas@imu.edu.my
}

\author{
Nafsiah Shamsuddin \\ Sedaya International \\ University College, \\ Kuala Lumpur, Malaysia \\ nafsiahs@sedaya.edu.my
}

\author{
Kai-Lit Phua \\ International Medical \\ University, \\ Kuala Lumpur, Malaysia \\ phuakl@imu.edu.my
}

\begin{abstract}
Malaysia is moving towards a developed country status and it is imperative that the healthcare provided be at a higher standard than it is today. As members of the healthcare team, nurses play an essential role in the provision of healthcare. As such it is timely that nurses' education be upgraded. As most of them only have a certificate or diploma in nursing, one way to upgrade the nurses is by providing opportunities for a baccalaureate degree. However, due to the shortage of nurses, nurses find it a challenge to enroll in a full-time on-campus programme. One way to help nurses meet the challenge is by providing an online distance learning programme to Malaysian nurses. And, to ensure the success of the online distance learning programme, it was realized that the nursing students need to be adequately prepared for an online learning environment. How much preparation will be determined, among other things, by their prior experience and skill in using technology as well as by their belief and attitude towards online distance learning. A survey was conducted on a cohort group of students during a face-to-face precourse orientation, that is, prior to the start of the online program. The findings of the survey are presented and discussed in the paper and implications for the future are highlighted.
\end{abstract}

Keywords : distance learning, online, nursing, perception, orientation

\section{Introduction}

Malaysia, with a population of 22 million people, is a rapidly developing country with a new industrial economy. The objective of Vision 2020 is that Malaysia will be a fully developed nation by the year 2020. In addition, in view of the development of a borderless world and a knowledge-based economy, Malaysians are being prepared to support the development of the knowledge-based economy (K-based economy) by 2010 (Abdullah, 2001). Consequently, the Ministry of Health's vision is to provide healthcare that is "equitable, affordable, efficient, technologically appropriate, environmentally adaptable and consumer friendly, with emphasis on quality, innovation, health promotion and respect for human dignity and which promotes individual responsibility and community participation towards an enhanced quality of life (Ministry of Health Malaysia, 2000)."

Nurses, as members of the healthcare team, play an essential role in the realization of this vision. The

Material published as part of these proceedings, either on-line or in print, is copyrighted by Informing Science. Permission to make digital or paper copy of part or all of these works for personal or classroom use is granted without fee provided that the copies are not made or distributed for profit or commercial advantage AND that copies 1) bear this notice in full and 2) give the full citation on the first page. It is permissible to abstract these works so long as credit is given. To copy in all other cases or to republish or to post on a server or to redistribute to lists requires specific permission from the publisher at Publisher@InformingScience.org nursing service provided by nurses must meet the expectations and needs of the people of a fully deve loped Malaysia. Nursing in Malaysia has remained almost in status quo since the country's independence. It has not made a recognisable impact within the healthcare delivery system. Its potential as a resource for delivering quality health care is untapped (Perala, 2001). The legacy of 
nurses as doctors" "handmaidens" remains to this day. This situation is obsolete and change must take place in the immediate future if nursing wants to be a force to reckon with within the healthcare delivery system. The nursing profession is facing many challenges that accompany the changes occurring in a rapidly developing country. Thus, it is important that the profession is proactive to meet these challenges. There are three categories of challenges: economic, demographic and technological.

Healthcare is a commodity, the cost of which is constantly rising. The emphasis of healthcare is efficiency and cost effectiveness. Clients today are more affluent and better informed. They expect value for the money they pay for healthcare. The challenge for nursing is to contain cost and to identify areas where healthcare is lacking in meeting the needs of the population. Subsequently, with improved healthcare people are living longer. The number of the aged population and people living with chronic diseases will rise. Care of the aged population and people living with chronic diseases will take a substantial amount of nursing service and time.

Science and technology will always be advancing. The challenge for nursing is thus to keep current of what is happening with the objective of being able to care for clients who have been given the latest treatment and/or medical technological interventions. Community-based nursing is inevitable for the present and the future. The spiraling cost of hospitalisation is resulting in healthcare being delivered more and more in the community. This shift in the delivery of care has implications for nursing practice. The emphasis of the present healthcare is on prevention, early detection of disease, wellness and client empowerment. The concept of holistic care needs to be emphasised. The whole person must be considered, with respect to the family and community, in his/her care, not just the disease. Today's nurses are expected to provide nursing care across the "traditional boundary (Rutty, 1998)." This means that nurses must be competent to provide nursing care in the hospitals as well as in the clients' home and anywhere (e.g. workplaces, factories, schools) in the community.

According to the Malaysian Minister of Health, Malaysia has about 32,000 registered nurses (RN). They comprise 80 percent of the total healthcare personnel in the country. Out of this number, 70 percent are working in the government sector (Chua, 2002). Chua emphasized that the nurses of the future are expected to know and to do more and better. They need to be equipped with a spectrum of knowledge, skills and attitude that will assist them in fulfilling their roles as effective health care providers. The practice of nursing needs to change from task orientation to role orientation. Hence, there is an urgent need for nurses to be upgraded in line with the changes surrounding the profession and in tandem with the requirements of the nation and society.

In most parts of the world nursing education has undergone changes in order to be relevant with the times (Rutty 1998, Le Storti, Cullen, Hanzlik, Michiels, Piana, Ryan \& Johnston, 1999; Perala, 2001; Freeman, Voignier \& Scott, 2002). It is inevitable that nursing educ ation in Malaysia will be heading in the same direction to ensure that the new graduates as well in-service nurses are prepared to work in the changed healthcare system.

The nursing curriculum needs to be dynamic and proactively responsive to changes. Other desired characteristics of such a nursing curriculum must include the promotion of critical thinking and life-long learning, theory that matches the practice, and a focus on outcomes (Freeman et al., 2002). Some of the important outcomes are critical thinking skills, life-long learning skills, technology skills, communication skills, primary care skills, management skills, collaborative skills and leadership skills.

The Ministry of Health has mandated that ten percent of the nursing population, that is, 3,200 nurses will have tertiary education in the future (Chua, 2002). At present, less than two percent of nurses have first degrees. Among the factors that hinder nurses to undertake degree programmes are the inability of employers to release nurses for study leave due to staff shortage. 
Today four public universities in Malaysia are conducting conversion degree programmes (diploma to bachelor) for RNs. These programmes are full-time, on-campus programmes. The number of nurses who are able to enroll in these programmes is small. To assist nurses obtain their degrees and at the same time maintaining full-time employment, a number of private universities are planning to offer nursing programmes at undergraduate and postgraduate levels. Some of the programmes will be offered either as traditional or online distance learning programmes. The latter, will provide more opportunities for nurses to undertake degree programmes.

\section{Why an Online Distance Learning Programme for Nurses?}

With the shortage of nurses in Malaysia, few nurses in the government service who wish to pursue further education are able to obtain a leave of absence from their place of employment. However, to ensure that the government's goal of having ten percent of the country's nurses have the opportunity to upgrade themselves, the government has encouraged local institutions of higher learning to establish part-time distance learning programs. An online distance learning programme is also believed to be ideal for those who prefer a flexible academic programme or who cannot leave their families behind to become full-time students.

Furthermore, online distance learning programmes will contribute to the Malaysian government's National Information Technology Agenda to help spur the development of the K-based economy. As the Deputy Prime Minister said in his speech on leveraging ICT towards a K-Based economy, "as technology moves from atoms to bits, from terrestrial space to cyberspace and from hardware to software, tomorrow's world wills shrink even more in space and time. The outpouring of information, unrestricted and uncensored, will create an information-based world, in which an outcome for management will be the challenge of managing knowledge-driven work (Abdullah, 2001)". Hence, the nursing profession will derive more benefits from their exposure to an online learning environment. Furthermore, new hospitals being built around the country are going paperless and in this context, it is imperative that we develop nursing champions of ICT who will help create an ICT using culture among their colleagues.

Technology can also help in career advancement. The Deputy Prime Minister stated that:

The Government has initiated efforts to promote and implement programmes for lifelong learning. Affordable accessibility to training courses and education programmes through the Internet or other ICT-related media will be provided so that Malaysians have the opportunity to acquire new competencies and qualifications for career advancement. IT kiosks and cyber centres will be set up by the Government, especially in the rural areas, to increase the accessibility to education and training. In addition, the establishment of community colleges, open universities and distance education will provide avenues for Malaysians to pursue tertiary education and upgrade their skills and qualifications (Abdullah, 2002).

The government, has, in short encouraged the use of ICT (information communication technology) in educational institutions. This is not only in tandem with the developments in education world wide where virtual campuses, e- learning but web-based courses are the trend and are observed to be effective in meeting the needs of today's matured learners (Jiang \& Ting, 1999; O'Malley, 1999). Furthermore, pedagogically, online learning has the potential to support constructivist learning where students are provided with a rich learning environment and where teachers and students become members of a learning community. This is where teacher facilitates and guides the learners and students may regard learning as a social and collaborative endeavour, suitable for adult and matured learners (Jonassen, Peck \& Wilson, 1999; Wilson, 1995). Hence, a nursing online programme offered from a distance is considered a solution for Malaysian nurses, particularly to help upgrade those already in the go vernment service but cannot leave their place of work. 
The International Medical University (IMU) is one of the private universities that has decided to help meet the government needs by offering an online distance learning programme. Prior to the start of its online program, the IMU invited the cohort group of students comprising 100 nursing tutors and medical assistants to a two-week face-to-face pre-course orientation on online learning.

The main objective of the pre-course programme was to orientate the potential students to the university's distance learning programme, the skills needed to become successful online learners and to address any shortcomings, particularly in terms of ICT skills. The topics covered included library and research skills, statistics, time and stress management, hands-on ICT training (MS Word, MS PowerPoint, Internet) and the use of VENuS, the learning management system for the Nursing programme. Students were made to understand the concept of online learning and what they will need to do online. The students were asked to try out VENuS and were taught how to log in and log out of VENuS; how to compose, send and receive e-mail messages; participate in the threaded discussion groups for collaborative learning and how to attach their assignments in the e-mail. The ICT component made up half of the time of the orientation programme with the other half given to the other non-ICT topics.

The participants were observed while they were using VENuS. It was part of a formative evaluation of the development of VENuS. Another objective was to determine their IT competencies and to obtain their perceptions to online learning. A brief description of VENuS is presented in the next section. The findings of the survey of the cohort group of students are presented and discussed in the section after that.

\section{The Online Distance Learning Program for Nursing}

The IMU distance online programme for nursing will be provided in the form of a web-based environment called VENuS (Virtual Education for Nursing Sciences). The platform for VENuS is WebCT, a learning management system from Canada and made available to the IMU based on the payment of a yearly license fee. Students will $\log$ into VENuS from where they are to retrieve the academic calendar, course schedule, course content, and assignments and participate in tutor moderated collaborative discussions. They will also have access to the faculty and e-moderators through e-mail. Students will also find chat rooms in which they will be able to have informal discussions or chat among themselves. The
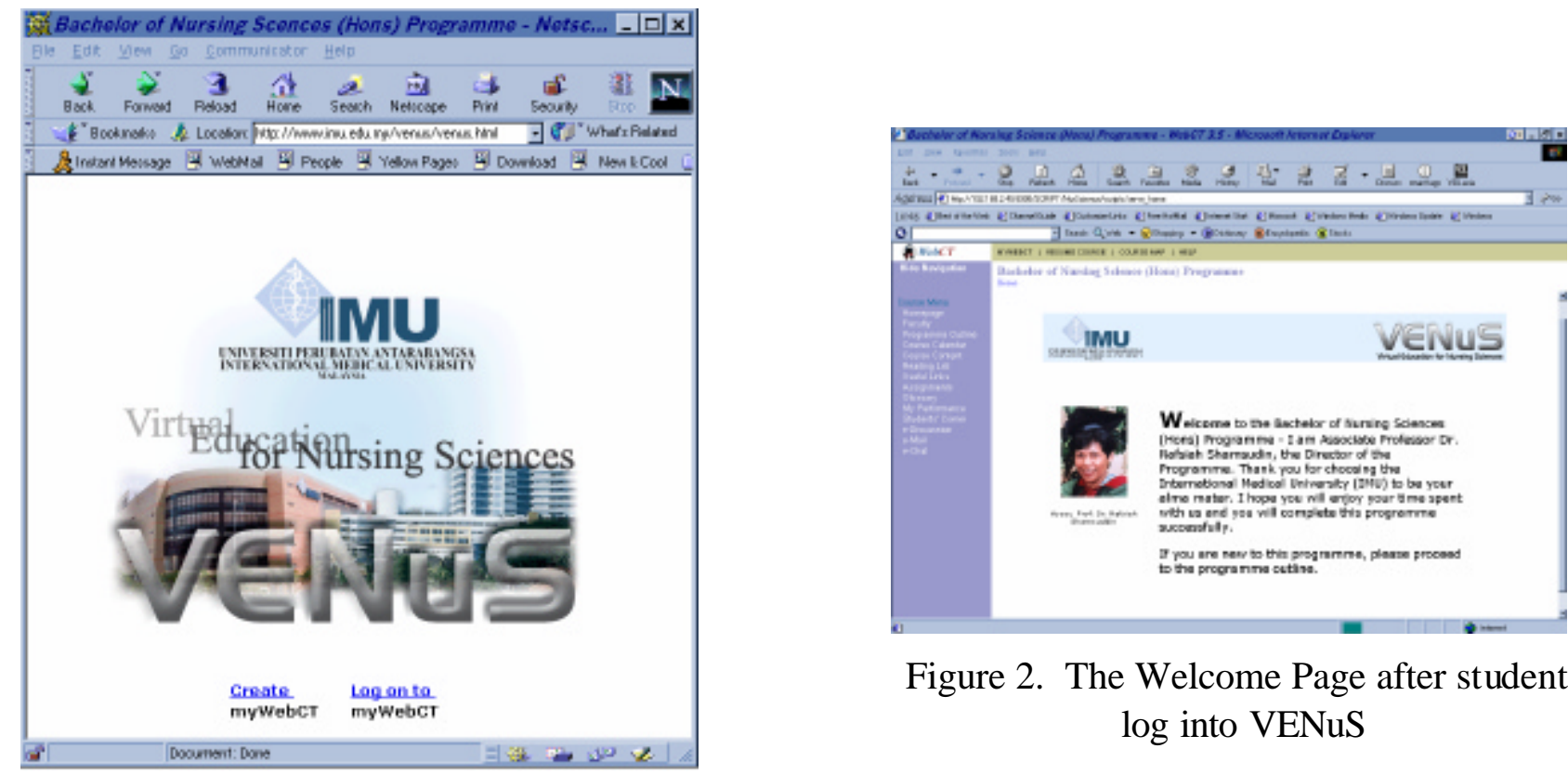

Figure 2. The Welcome Page after students $\log$ into VENuS

Figure 1. What students see when they first enter VENuS 
development of learning communities have been planned in primarily to overcome the factors of loneliness or isolation, typically experienced by distance learners. Figures 1 and 2 are examples of what VENuS looks like.

VENuS is designed by a team comprising subject-matter experts, an instructional designer and a webmaster. Part of the VENuS team had prior experience designing OLIS (Online Learning Interactive System) for the medical students of the IMU and had been graduate degrees in Instructional Technology.

When designing VENuS, much consideration was given to the preparation of a learner-friendly environment. For example, the course content was not only arranged in separate sections but the style of writing was edited to convey a warm feeling to the students. To promote collaborative learning whereby students are expected to be engaged in the online discussions with their tutor and fellow students, marks will be given and made part of the formative course assessment. The nursing curriculum committee had also decided that the marks given would be based on the quality of postings rather than simply on the frequency or length of postings. Collaborative discussions would make up to 20 percent of the total course marks.

\section{Are Malaysian Nurses Prepared for Online Learning?}

Those in the nursing profession in Malaysia are generally perceived to be less academically inclined as academic requirements to enter the nursing profession are lower than required for other professions. And, because the teaching responsibilities of those in the cohort group do not necessarily require them to use computers, they were also not expected to be computer literate, a pre-requisite to succeed in an online distance learning programme.

To ascertain whether the cohort group of nurses for Malaysia's first online distance learning programme was ready, a survey was carried during the pre-course orientation. It was important for the survey to be carried out to determine the profile of students and to identify their level of ICT literacy to help determine how to address any shortcomings prior to the start of the programme. This was to help students cope better with the online distance learning programme as well as to minimize the rate of attrition. It is to be noted that while the cohort group will be representative of nursing tutors in the country, they were not expected to be representative of the whole nursing profession.

The cohort group of students or respondents of the survey comprised nurses and medical assistants with more than fifteen years of working experience in the Ministry of Health. They were, at the time of the survey, employed in the colleges of nursing from around the country. These nursing colleges were located in the towns or cities where ICT facilities, in partic ular, access to the Internet was available.

The ministry had identified them to be the first batch of nurses and medical assistants for the

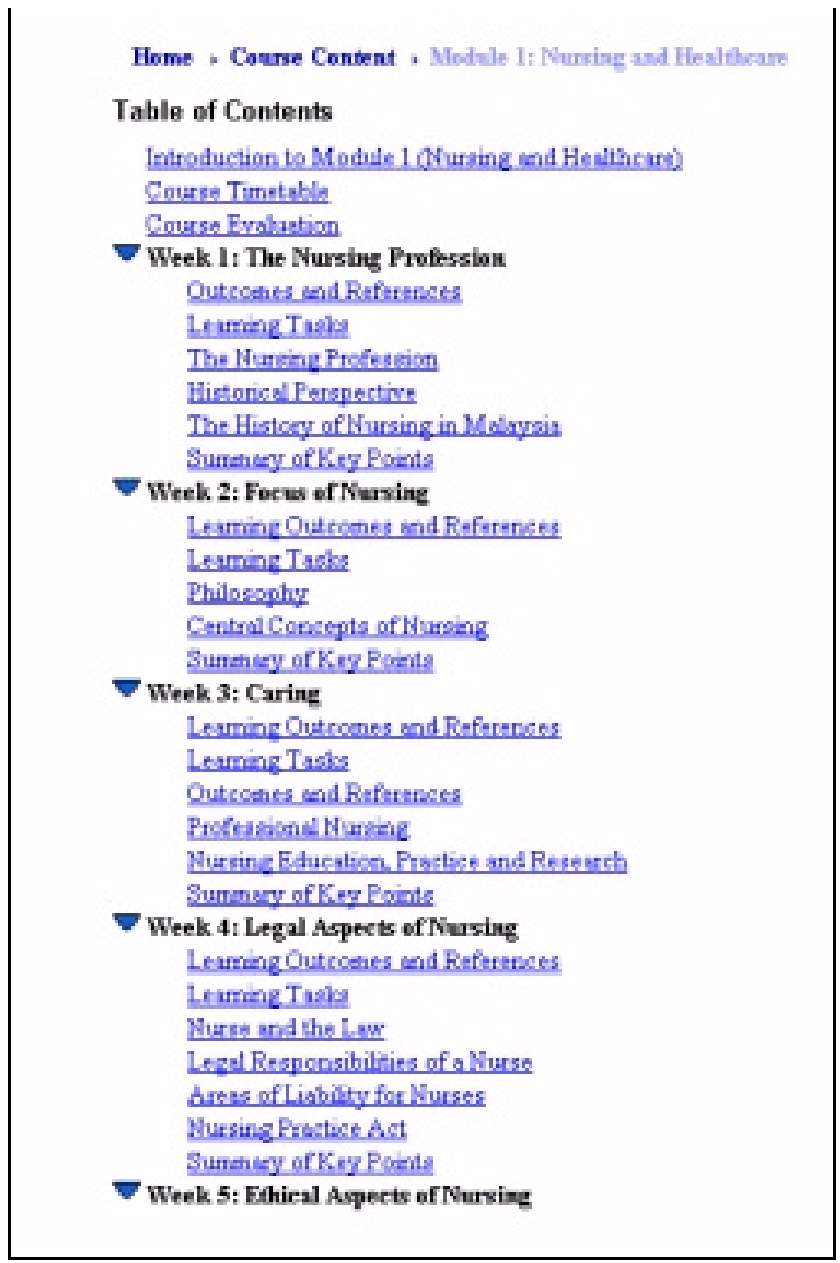

Figure 3. Part of the Table of Contents in VENuS 
country's first online distance learning program for nur sing primarily because their main job was to train new nurses or medical assistants at the Diploma level. Hence, these tutors were a priority for the programme primarily because their role and contributions to the health industry would have the most impact particularly on the nursing profession.

\section{Sample and Methodology}

A total of 89 nurses and medical officers responded to the survey carried out during their two-week preorientation to online learning at the International Medical University. They were part of the 100 ind ividuals who made up the first cohort group of nursing students identified by the ministry of health for the IMU nursing program. The survey form was administered towards the end of their second week. The forms were distributed to every participant and collected before the orientation programme ended. Respondents could remain anonymous.

The survey form was designed to determine the state of readiness of the first cohort group of students for an online distance learning program. Among the questions asked were their previous ICT experience and what they felt about online learning after the two-week pre-course orientation programme. In short, it was first, to determine their level of computer literacy. This is important to know because being ICT literate is one of the pre-requisites for an online distance learning program. Their responses to this set of questions would enable the institution to make the necessary adjustments or to incorporate the necessary exposure during the implementation of the program. The next set of questions was on their belief of online learning. This was to assess their perception and attitudes that could make a difference to their success in the online distance learning programme.

As expected, the cohort group comprised mostly females (88.8\%). They ranged in age from 34 to 49 years old. Most of the respondents were between the ages of 39 and 47 (87.4\%). The median age was 44 years old. Hence, the first group of students that were identified for the country's first online nursing distance program are a matured group of learners with many years of work experience and who, typically, would be married with children in their teens.

It was found that 82 of the respondents, that is, $93.2 \%$ had more than 15 years of work experience. About half of the group had between 20 and 23 years of work experience. Only two had seven to 10 years of work experience and seven $(8 \%)$ respondents had more than 25 years of experience working either as a nurse or a medical officer.

\section{Findings}

It was somewhat surprising to know that a significant number of the respondents, that is $80(89.9 \%)$ of the 89 who responded, had a personal computer at home. On the other hand, in view of the government's repeated calls for Malaysians to be computer literate, it should not be surprising. In addition, 53 or $38.2 \%$ had access to the Internet from their homes. Respondents were also asked whether they needed help in using either the computer or the Internet. The majority, that is, $77.7 \%$ indicated that

\begin{tabular}{|l|l|l|l|l|l|}
\hline & $\begin{array}{l}\text { Not at all } \\
\mathrm{N}(\%)\end{array}$ & $\begin{array}{l}<2 \text { hours per } \\
\text { week } \\
\mathrm{N}(\%)\end{array}$ & $\begin{array}{l}\text { 2-10 hours } \\
\text { per week } \\
\mathrm{N}(\%)\end{array}$ & $\begin{array}{l}11-20 \text { hours } \\
\text { per week } \\
\mathrm{N}(\%)\end{array}$ & $\begin{array}{l}>20 \text { hours per } \\
\text { week } \\
\mathrm{N}(\%)\end{array}$ \\
\hline Using the computer & $5(5.7 \%)$ & $32(36.4 \%)$ & $39(44.3 \%)$ & $7(8 \%)$ & $5(5.7 \%)$ \\
\hline Using the e-mail & $60(68.2 \%)$ & $20(22.7 \%)$ & $4(4.6 \%)$ & $4(4.6 \%)$ & $0(0 \%)$ \\
\hline Using the Internet & $46(52.3 \%)$ & $27(30.7 \%)$ & $10(11.4 \%)$ & $3(3.4 \%)$ & $2(2.3 \%)$ \\
\hline
\end{tabular}

Table 1: Average time spent on the computer, e-mail and the Internet in the last six months 
they did. This meant that while the majority of respondents had computers at home and had access to the Internet, the latter finding implied that they were not the main users of the computer or Internet at home. It was more likely to be their spouse or their children. This confirms that the pre-course orientation programme should include teaching the participants to use MS Word, MS PowerPoint and the Internet.

When asked how much time have they spent using the computer in the last six months prior to the survey, five $(5.7 \%)$ indicated that they did not use the computer at all. Thirty-two or $36.4 \%$ indicated that on average, they had used the computer for less than two hours each week. Thirty-nine or $(44.3 \%)$ had spent roughly between two and 10 hours a week on the computer in the last six months. Twelve of the respondents $(13.6 \%)$ spent an average 11 hours or more a week. This is highlighted in Table 1.

Table 1 also indicates the respondents' past six months' experience with e-mail and the Internet. A majority $(68.2 \%)$ of the respondents had indicated they had not used the e-mail at all. Twenty $(22.7 \%)$ spent an average of less than two hours a week e-mailing. Another four (4.6\%) indicated that they spent an average of between two and 10 hours e-mailing. Similarly two others (4.6\%) spent between an average of between 11 and 20 hours e-mailing.

When asked about their Internet experience (see Table 1) over the past six months, $46(52.3 \%)$ ind icated that they did not access the Internet at all. Twenty-seven $(30.7 \%)$ had accessed the Internet for two hours or less on average, per week. Another 10 respondents $(11.4 \%)$ stated that they spent an average of between two and 10 hours a week. Five others $(5.7 \%)$ spent an average of more than 11 hours on the Internet each week. Hence, their exposure to $\mathrm{VENuS}$, particularly on how to send and read postings, participate in online collaborative discussions were necessary during the pre-course orientation programme.

Table 2 highlights the responses obtained from the respondents on what their belief towards online learning was. This was represented by 13 statements (see Table 2). When asked if online learning will make them more anxious, $39(44.3 \%)$ of the respondents agreed that it would. Another $12(13.6 \%)$ said that they strongly agreed that online learning will make them more anxious. Twenty-one $(23.8 \%)$ respondents felt that they would not be more anxious than they already were. Another $16(18.1 \%)$ were not sure whether online learning would make them more anxious.

On whether they felt that online learning (system) would be easy to use, the majority, that is, 46 (53.5 $\%$ ) implied that they would be able to manage easily. Thirty $(12.8 \%)$ disagreed or strongly disagreed with the statement. In short, they anticipated that the online system would not be easy to use. About a third, or $29(33.3 \%)$ of the respondents were not sure. Respondents were also asked whether they felt they could cope as students of online learning, more than half, that is, 56 (64.4\%) of the group believed that they would. About a third, or $29(33.3 \%)$ of the respondents were not sure and only two others $(2.3$ $\%)$ felt apprehensive.

When asked for their perception on whether online learning represented an interesting delivery medium, the majority, $79(90.8 \%)$ believed that it was, indeed, interesting. Only seven respondents $(8.1 \%)$ were unsure and only one other person $(1.2 \%)$ believed it was uninteresting. It was also found that $81(94.2$ $\%$ ) believed or strongly believed that online learning will offer them a positive learning experience for them. Only four $(4.7 \%)$ were not sure about the experience being positive and only one (1.2\%) did not believe that it would bring a positive learning experience.

On whether they would take some time to get used to online learning, nine respondents $(10.3 \%)$ believed that they will be able to get themselves comfortable immediately, five $(5.8 \%)$ were not sure about this while an overwhelming majority felt that they will need some time before they could get used to online learning. The latter was agreed or strongly agreed by $71(83.9 \%)$ of the respondents. 


\begin{tabular}{|l|l|l|l|l|l|}
\hline & $\begin{array}{l}\text { Strongly } \\
\text { Disagree } \\
\mathrm{N}(\%)\end{array}$ & $\begin{array}{l}\text { Disagree } \\
\mathrm{N}(\%)\end{array}$ & $\begin{array}{l}\text { Unsure } \\
\mathrm{N}(\%)\end{array}$ & $\begin{array}{l}\text { Agree } \\
\mathrm{N}(\%)\end{array}$ & $\begin{array}{l}\text { Strongly } \\
\text { Agree } \\
\text { N } \%)\end{array}$ \\
\hline Make me more anxious & $4(4.6 \%)$ & $17(19.3 \%)$ & $16(18.2 \%)$ & $39(44.3 \%)$ & $12(13.6 \%)$ \\
\hline Easy to use & $2(2.3 \%)$ & $9(10.5 \%)$ & $29(33.7 \%)$ & $39(45.4 \%)$ & $12(13.6 \%)$ \\
\hline Something I can cope with & $1(1.2 \%)$ & $1(1.2 \%)$ & $29(33.3 \%)$ & $51(58.6 \%)$ & $5(5.8 \%)$ \\
\hline $\begin{array}{l}\text { An interesting delivery } \\
\text { medium to use }\end{array}$ & & $1(1.2 \%)$ & $7(8.1 \%)$ & $58(66.7 \%)$ & $21(24.1 \%)$ \\
\hline $\begin{array}{l}\text { A positive experience } \\
\text { Take some time to get } \\
\text { used to }\end{array}$ & $2(2.3 \%)$ & $7(8.1 \%)$ & $5(5.8 \%)$ & $46(52.9 \%)$ & $27(31.0 \%)$ \\
\hline $\begin{array}{l}\text { Allows me to interact with } \\
\text { the online course facilita- } \\
\text { tor(s) }\end{array}$ & & $1(1.2 \%)$ & $4(4.7 \%)$ & $57(66.3 \%)$ & $24(27.9 \%)$ \\
\hline $\begin{array}{l}\text { Generate interesting online } \\
\text { discussions with fellow } \\
\text { students }\end{array}$ & & $4(4.6 \%)$ & $53(60.9 \%)$ & $30(34.5 \%)$ \\
\hline $\begin{array}{l}\text { A convenient way to learn } \\
\text { Makes learning more effi- } \\
\text { cient }\end{array}$ & $1(1.1 \%)$ & $4(4.6 \%)$ & $23(26.1 \%)$ & $47(53.4 \%)$ & $13(14.8 \%)$ \\
\hline $\begin{array}{l}\text { Offers a rich learning ex- } \\
\text { perience }\end{array}$ & & & $7(8.1 \%)$ & $56(64.4 \%)$ & $24(27.6 \%)$ \\
\hline $\begin{array}{l}\text { Something I look forward } \\
\text { to doing for my profes- } \\
\text { sional development }\end{array}$ & & & $7(10.2 \%)$ & $47(53.4 \%)$ & $32(36.4 \%)$ \\
\hline $\begin{array}{l}\text { Provide me with a flexible } \\
\text { able for me as a full-time } \\
\text { employee }\end{array}$ & & $11(12.6 \%)$ & $47(54.0 \%)$ & $28(32.2 \%)$ \\
\hline
\end{tabular}

Table 2: Belief in Online Learning

Respondents were also asked whether they believed online learning would allow them to interact with the online course facilitator(s). An overwhelming majority had no doubt that this will be possible. This was agreed or strongly agreed by $83(95.4 \%)$ of the group of respondents. Only four $(4.6 \%)$ were unsure about this. Further to that, respondents also believed that they would experience interesting discussions online. Seventy-seven $(89.5 \%)$ agreed or strongly agreed to the latter. Nine $(10.5 \%)$ were not sure whether they would experience interesting discussions.

"Would online learning be a convenient way to learn?" was the next question asked. Sixty-six (76.7 \%) of those who responded either agreed or strongly agreed that online learning would offer convenience to students. Seventeen (19.8\%) individuals were unsure and only three (3.5\%) thought otherwise. On whether online learning would be more efficient, $60(68.2 \%)$ respondents agreed or strongly agreed that it would. Twenty-three $(26.1 \%)$ were unsure and only five $(5.7 \%)$ did not think so. When asked whether online learning would offer a rich learning experience, the majority, that is, 80 (92\%) believed that it would. Seven $(8.1 \%)$ were not sure. 
The next question was on whether online learning is something that they would look forward to doing for their professional development. Seventy-nine $(89.8 \%)$ believed so. Only seven $(10.2 \%)$ were unsure. On whether the respondents believed that online learning would offer a flexible learning environment for them as full-time employees, 75 (86.2\%) agreed or strongly agreed. Eleven (12.6\%) were not sure. Only one respondent $(1.2 \%)$ did not think that online learning would offer the flexibility.

One other question was on whether they understood the requirements of online learning very well and whether they were sure to succeed. Nine $(10.7 \%)$ stated they were unsure, $43(51.2 \%)$ thought that they understood and believed they would succeed. Thirty-two or $38.1 \%$ of the respondents were very definite that they understood what online learning required and felt sure about succeeding.

Finally, when participants were asked through an open-ended question on what they generally felt about the pre-course orientation on the ICT and online component, many felt that the ICT exposure should be longer. Most felt that the orientation had helped them develop or improve their ICT skills; provided them new skills, particularly in e-mailing and the use of the Internet and it was helpful that they were able to use VENuS.

\section{Discussions}

Overall, the respondents regard the prospect of doing an online distance learning programme as positive. They view it as an interesting, convenient and rich learning experience that will assist them in their professional development. They also believed that online learning would offer them flexibility so that they will not need to leave the job or the family and they could carry out their learning activities around work and the family. Hence, it would be a convenient way to learn. Generally, they felt that they could cope given time. They are positive about the interactions that they will get with their online facilitators.

It is not surprising to note that the majority of the respondents are anxious about enrolling in an online distance learning programme. This is because online learning is new to Malaysian nurses. The majority of nurses are unfamiliar with online learning and this was probably the biggest cause of anxiety, particularly among those who were not frequent computer users. It appears that the respondents are aware of the requirements to be successful online learners in that they had to be technologically comfortable and competent. The majority are prepared to face the challenges and coupled with their positive attitudes, the attrition rates among them may be minimised.

The findings have implications for the university that is offering the online programme and for the students that are enrolling. From the perspective of the university, an orientation programme prior to the commencement of the actual programme prepares the students for what are expected out of them. At the same time, it (orientation programme) informs the students what they can expect out of the online programme and what they have to do to be successful learners.

It was greatly felt that students will need help especially at the start of their programme in the first semester. The assistance that students require may go on until the completion of the programme. The assistance that students require can be personal or academic. Help line needs to be in place 24 hours a day. Responses to queries should be handled within one or two working days. A mentor-mentee system will also lend a personal touch to an impersonal online programme. In other words, providing a hi-touch environment to an impersonal hi-tech environment needs to be built in.

From the viewpoints of potential students, they realized the need to equip themselves with ICT skills, particularly in the use of the e-mail and other interactive features of the e-learning platform such as online discussions and chat rooms, before enrolling in an online programme. Based on the discussions with the participants, most were willing to do what it took to overcome their lack of ICT skills. On the lack of access to the Internet, those who did not have Internet access in their homes were ready to subscribe to an Internet Service Provider and had asked for details on how to subscribe to one. At one 


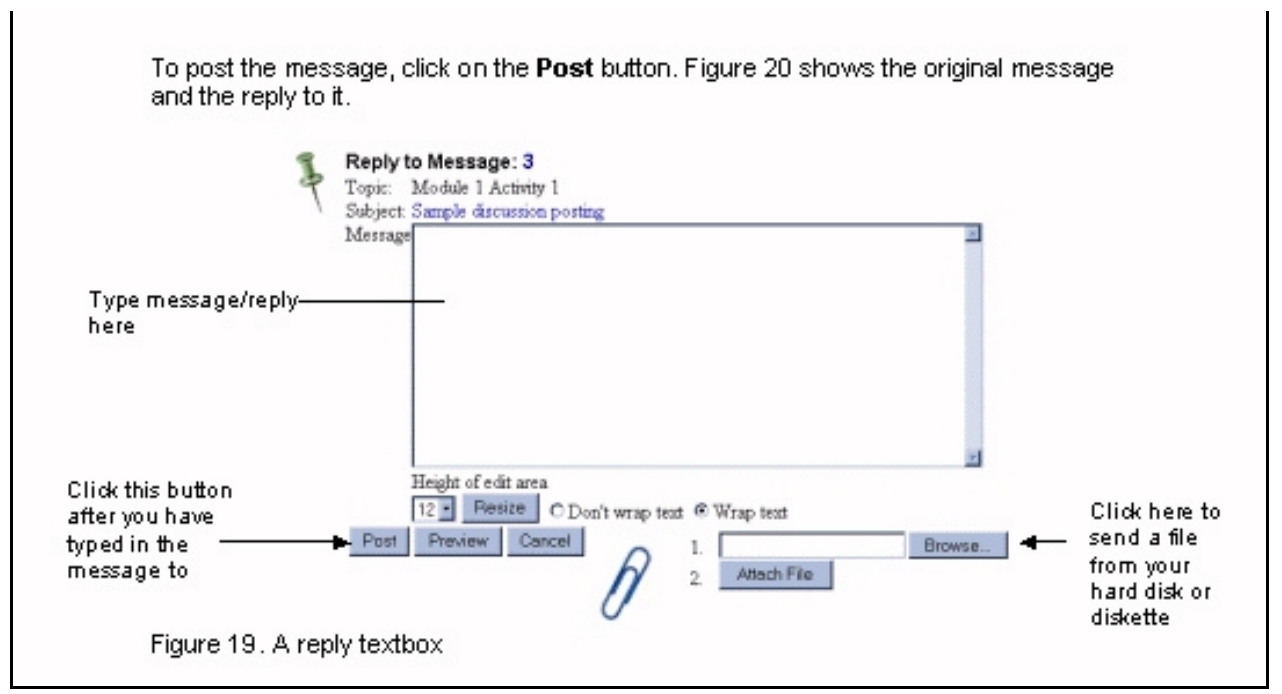

Figure 4. Instructions on how to compose and send messages to the e-discussion group in $\mathrm{VENuS}$

point, when the students were asked how long they have had their computers at home, many stated that they were already considering buying the latest computer model for their programme of study.

Other requirements include being organized and disciplined as well as being accountable for their own learning. The teachers will only be facilitators of learning. In addition, the university realizes the need to prepare a guidebook on how to use the e-learning platform and another guidebook on how to succeed as an online learner. While the former serves to address the technical or the more technological issues, the latter would serve as a learning companion focusing on significant issues such as attitude, timemanagement, motivation, communication skills, persistence, perseverance and a sense of community. Hence, the nursing faculty had recommended the preparation of a Nursing Student Companion that would comprise the VENuS User Guide and a guide on how to succeed as an online student. The VE$\mathrm{NuS}$ User Guide had been field-tested with a few students after the pre-course orientation programme and the guide on "How to Succeed as an Online Student" received positive feedback from colleagues at the IMU. The Companion will be made available in hard copies and given to the student upon registration. Figures 4 and 5 are examples of some of the instructions given to students as part of the online companion.

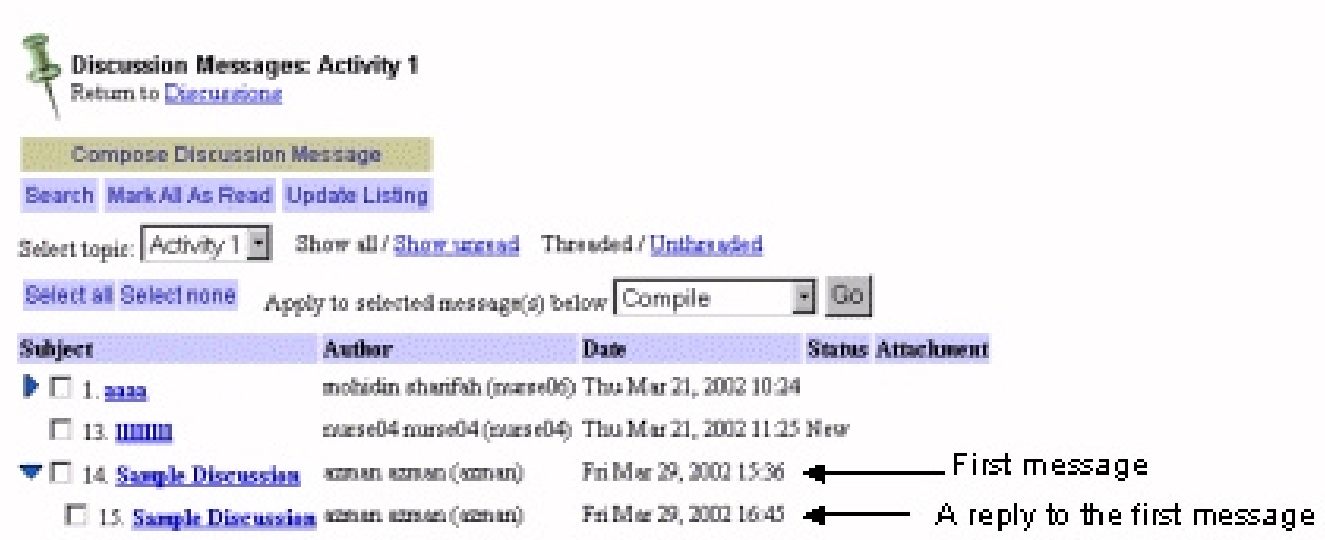

Figure 20. e-Discussion with a reply

Figure 5. Instructions on using the threaded discussion in VENuS 


\section{Conclusion}

To support the country's need to upgrade at least 10 percent of the 32,000 nurses by enabling them to have a first degree in nursing and to enable nurses to continue working as well as to keep their family life intact, an online distance learning mode for a baccalaureate program for nursing was considered a solution. This is also in view of the fact that the Malaysian government considers ICT as a suitable platform for lifelong education in general and tertiary education in particular. The National IT Agenda is in place to help pave the way to the development of a K-based economy and efforts to enable the population to afford computers as well as to afford Internet access are being made. An online distance learning programme would also enable nurses to become comfortable with the use of technology in line with the need to develop nurses who will soon be working in paperless hospitals that have been built or are being built in various parts of the country.

A survey to determine the nurses' current set of ICT skills and their perceptions of online learning was carried out among participants who had been identified by the Ministry of Health Malaysia to enroll in what could be the country's first online distance learning programme for nurses. They participated in a two-week orientation programme that was designed to equip them with the skills (including library, research, statistics, time and stress management) required to succeed as a distance student and to help them understand what was required in online learning. The orientation also exposed them to VENuS, the online learning environment that was designed to deliver the nursing programme and how the various features in VENuS fitted into their learning activities.

The findings revealed that while most of the first cohort group of students had computers at home, only a third of the group had Internet access at home. More than half of the group did not have e-mail addresses or been on the Internet. Hence, their lack of Internet experience meant they had to learn how to e-mail and participate in collaborative online discussions prior to enrolling at the IMU.

On the other hand, it was found that as a result of the orientation, most had understood what an online programme was and what was required of them as students. It was learnt that they generally believed that online learning would offer them the flexibility they needed and the convenience that would come with it. Most believed that online learning would contribute to a positive learning experience and provide them with an interesting as well as a rich learning experience. Although more than half of the group was anxious with online learning, they were determined to succeed in the programme.

The findings ascertained that the university offering such a programme generally need not worry about nurses not having computers at home. If they did not or had old computers, they were willing to buy a new one. However, the university would have to ensure that the ICT skills of students are properly addressed by the time the students are enrolled and that pre-course orientation programmes held to address the ICT skills prior to the start of the programme would not only be useful but necessary. The ICT skills that need to be addressed include how to use MS Word, MS PowerPoint, e-mail, send, read and contribute to online postings to collaborative learning groups and how to send assignments via e-mail. Also important is the exposure to Internet and how to use and find information on the World Wide Web.

It is recommended that ICT skills be made part of the pre-course orientation program and that it be given over more a period of more than one week to provide proper hands-on experience and to build a higher level of confidence especially among those who are not regular computer users.

\section{References}

Abdullah A. Badawi (2001). Leveraging ICT towards knowledge economy. Speech delivered at the opening ceremony of The Malaysia Corporation Information Technology Conference \& Exhibition 2001, November 5, Sunway Pyramid Convention Centre, Bandar Sunway (unpublished). 
How Prepared are Malaysian Nurses

Abdullah A. Badawi (2002). Speech delivered at the opening ceremony of the ASEM lifelong learning initiative International Conference on Lifelong Learning, May 13, 2002, Asia Europe Institute, University of Malaya, Kuala Lumpur (unpublished).

Chua, J. M. (2002). Speech delivered at the opening ceremony of the International Nursing Conference: Advances in Nursing Practice, 4 October, 2002, The Legend Hotel, Kuala Lumpur (unpublished).

Freeman, L. H., Voignier, R. R. \& Scott, D. L. (2002). New curriculum for a new century: Beyond repackaging. Journal of Nursing Education, 41(1), 38-40.

Jiang, M. \& Ting, E. (1999). A study of students' perceived learning in a web-based online environment." Retrieved October 16, 2001 from the World Wide Web http://www.ericit.org/fulltext/IR020484.pdf

Jonassen, D. H.; Peck, K. L. \& Wilson, B. G. (1999). Learning with technology: A constructivist perspective. Upper Saddle River, NJ: Merril/Prentice-Hall.

Le Storti, A. J., Cullen, P. A., Hanzlik, E. M., Michiels, J. M., Piano, L. A., Ryan, P. L. \& Johnson, W. (1999). Creative thinking in nursing education: Preparing for Tomorrow's Challenges. Nursing Outlook, 47(2), 62-66.

O’Malley, J. (1999). Students perceptions of distance learning, online learning and the traditional clas sroom. Online Journal of Distance Learning Administration, 2(4). Retrieved October 16, 2001 from the World Wide Web http://www.westga.edu/ distance/omalley24.html

Ministry of Health Malaysia (2000). Health in Malaysia: Achievement and Challenges. KL: Ministry of Health Malaysia.

Perala, M. L. (2001). Guest editorial. Nursing in the new millennium: Full utilization of the potential benefits of nursing for society. International Journal of Nursing Practice, 7(2), 61-62.

Rutty, J. (1998). The nature of philosophy of science, theory and knowledge relating to nursing and professionalism. Journal of Advanced Nursing, 28(2), 243-250.

Warr, J., Gobbi, M. \& Johnson, S. (1998). Expanding the nursing profession. Nursing Standard, 12(31), 44-47.

Williamson, T. \& Harris, K. (2000). A new role in practice development. Nursing Standard, 14(35), 54-56

Wilson, B. G. (1995). Metaphors for instruction. Why we task about learning environments. Educational Technology, 35 (5), 25-30.

Wisdom, K. J. (2002). Nursing roles in the health care delivery system. In Chitty, K.K. (Ed.). Professional Nursing: Concepts \& challenges $\left(3^{\text {rd }}\right.$. Ed.). Philadelphia, Saunders, chapter 14.

\section{Biographies}

Zoraini Wati Abas is an Associate Professor in the Nursing section of the Faculty of Medical Sciences at the International Medical University. She is responsible for the design and development of VENuS, the delivery platform for the nursing program. She received her Ed.D. in Instructional Technology from the Northern Illinois University, DeKalb, Illinois. Her research interests include collaborative learning, the impact of e-learning and ICT for youth development. She has served as consultant for several webbased projects related to teaching and learning at both the secondary and tertiary levels of education.

Nafsiah Shamsuddin is Head, School of Nursing at the Sedaya International University College in Kuala Lumpur. She had contributed to the curriculum and content development of VENuS when she was Associate Professor at the Nursing section of the Faculty of Medical Sciences at the International Medical University. She received her Ph.D. in nursing from University of Wales College of Medicine, Cardiff, Wales, United Kingdom. Her interest in research is in holistic nursing and nursing education. She also serves as consultant in curriculum development and nursing education.

Kai-Lit Phua is a lecturer in the Community Medicine section of the Faculty of Medical Sciences at the International Medical University. He previous work experience includes five years with the Maryland Department of Health and Mental Hygiene in Baltimore, USA. He received his PhD from Johns Hopkins University. His research interests include areas related to public health policy. 